\title{
A CRÍTICA SOCIOLÓGICA E DIALÉTICA DE ANTONIO CANDIDO: ENTRE O FATO SOCIAL E A EXPRESSÃO ARTÍSTICA
}

\author{
COSTA, Fabrício Lemos da ${ }^{1}$ \\ HOLANDA, Sílvio Augusto de Oliveira ${ }^{2}$
}

\begin{abstract}
RESUMO: Este ensaio reflete sobre o método crítico do brasileiro Antonio Candido, cuja peculiaridade consiste em demonstrar, dialeticamente, a particularidade da obra literária, em que o externo, ou seja, os fatores sociais, tornam-se internos, convertendo-se em expressão artística. Para o crítico, faz-se mister considerar na interpretação, o social como elemento da organicidade do texto e da composição do enredo, e não apenas como ilustração do contexto em que o texto está inserido. Assim, interessam-no como assuntos relacionados ao dinheiro, ao capitalismo, ao dote e ao casamento, por exemplo, tornamse parte do discurso literário e da conjuntura geral da obra, como o fez na análise do romance Senhora, de José de Alencar. Nossa reflexão concentrar-se-á, sobretudo a partir de A Literatura e Sociedade, publicado em 1965, no contexto da ditadura militar.
\end{abstract}

PALAVRAS-CHAVE: Antonio Candido, Dialética, Expressão Artística, Crítica Sociológica.

\section{ANTONIO CANDIDO'S SOCIOLOGICAL AND DIALETIC CRITICISM: BETWEEN SOCIAL FACT AND ARTISTIC EXPRESSION}

\begin{abstract}
This essay aims at reflecting upon Antonio Candido's critical method, whose peculiarity consists of a dialectical demonstration of the literary work's uniqueness, whereas the external, as social facts, become internal ones turned in artistic expression. According to the criticist it is imperious to consider in interpretation the 'social' as an element of the text's organisation and the theme's composition, and not only as a context illustration. Thus, it interests him topics related to money, capitalism, dowry and marriage, for instance as part of the literary and general work speech as likely done in the analysis of José de Alencar's novel entitled Senhora. Our reflection will be focused mostly
\end{abstract}

\footnotetext{
${ }^{1}$ Mestrando em Estudos Literários, Universidade Federal do Pará-UFPA. E-mail: fabricio.lemos1987@yahoo.com.br

${ }^{2}$ Professor de Literatura Brasileira, Universidade Federal do Pará-UFPA. E-mail: eellip@ hotmail.com
} 
on the work A Literatura e Sociedade published for the first time in 1965, within the military regime's context.

KEYWORDS: Antonio Candido, Dialetics, Artistic Expression, Sociological Criticism.

Antonio Candido, professor emérito da Universidade de São Paulo (USP), é autor de diversos livros, entre eles estão: Introdução ao método crítico de Sílvio Romero (1945), Brigada Ligeira (1945), Ficção e Confissão (1956), Formação da Literatura Brasileira (1959), Tese e Antítese (1964), Parceiros do Rio Bonito (1964), Literatura e Sociedade (1965), Vários escritos (1970), A educação pela noite (1987) e $O$ discurso e a cidade (1993), além de muitos outros ensaios divulgados em jornais, como "Sagarana" (Diário de S. Paulo, 11 jul. 1946). Neste estudo, abordaremos sua reflexão em torno da dialética entre os elementos externos e internos na composição das obras literários, responsáveis pela expressividade, assim como são fundamentais para uma interpretação coerentemente válida, como fica evidente desde a sua tese intitulada Introdução ao método crítico de Sílvio Romero, escrita para fins de docência na Universidade de São Paulo.

Antonio Candido, em Literatura e Sociedade, formula sua concepção dialética da crítica no capítulo "Crítica e Sociologia", intitulando-a "tentativa de esclarecimento". Esse pressuposto é importante, porque demonstra a total consciência do crítico no que tange à discussão da relação do social no texto literário. Antonio Candido, como se sabe, foi leitor da escola americana, o New Criticism, assim como sua formação está ligada à antropologia funcional inglesa. Para isso, esclarece em sua reflexão a incapacidade de pensar o texto literário fora do viés interno e externo, como fora comum na perspectiva da crítica do século XIX, em que Taine é representante, e a abordagem formal que entende a obra fora de qualquer manifestação externa. Assim, "hoje sabemos que a integridade da obra não permite adotar nenhuma dessas visões dissociadas; e que só a podemos entender fundindo texto e contexto numa interpretação dialeticamente íntegra”. (CANDIDO, 1967, p. 04)

Vale ressaltar, ainda, que a crítica de Antonio Candido tem também como base a sua experiência no jornalismo, sobretudo a partir da Revista Clima, além do seu período dedicado à militância, como é possível perceber no texto $O$ direito à literatura. Para o professor crítico, a parte concreta deve ser analisada como fator de intersecção entre o social e a manifestação interna ao texto. Dessa forma, Candido sublinha os fatores sociais como formadores da estrutura em que se dá em "correlação sistemática das partes" (CANDIDO, 2005, p. 05). Faz-se mister esclarecer que o termo "estrutura" usado por Antonio Candido não se confunde com o 
estruturalismo abstrato, herdeiro de Saussure, evidenciado, principalmente por Claude LéviStrauss. Com Candido, é antes um "campo complexo", e não um conceito. Segundo Claude Lévi-Strauss em Antropologia estrutural: dois, capítulo "A estrutura e a forma", "a estrutura não tem conteúdo distinto: ela é o próprio conteúdo, apreendido numa organização lógica concebida como propriedade do real" (LÉVI-STRAUSS, 1993, p. 121)

Portanto, essas correlações são fundamentais para entendermos a que nível a estrutura é formulada em Literatura e sociedade, pois enquanto os estruturalistas não se interessam pelo contexto, devendo ser "descartado" da metodologia; Candido, por outro lado, pensa-o, dialeticamente, como parte de uma forma que é a obra. Os estruturalistas, como sabemos, mesmo tendo consciência do viés social, não o utilizam em suas análises, em parte pela própria influência ligada à linguística estrutural de Saussure, o qual colocou como cerne a diferença entre langue e parole, o coletivo e o individual, respectivamente. De acordo com David Viñas Piquer, "el punto de partida del Estructuralismo se encuentra en los métodos de la linguística contemporánea, sobre todo en las intuiciones de Ferdinand Saussure. De hecho, el Estructuralismo literário consiste en aplicar a la literatura el modelo metodológico empleado por los linguistas" (PIQUER, 2002, p. 4331)

De outro modo, Antonio Candido pretende fundir texto e contexto, analisando-os a partir de uma organicidade, termo caro à crítica literária, desde Aristóteles, em que no crítico brasileiro é fundamental, porque se condiciona como motivação para os vários elementos, como os fatores externos em que serve para "focalizar aspectos sociais que envolvem a vida artística e literária" (CANDIDO, 1967, p. 21). Nesse sentido, para o trabalho de interpretação da obra, Candido defende o não radicalismo dos estruturalistas, já que estes negam a história e acabam comprometendo as análises que são importantes numa perspectiva mais contemporânea, mas ao mesmo tempo, o crítico tem consciência dos avanços no que diz respeito às terminologias, assim como uma maior motivação para análises mais analíticas da obra literária. Assim, defende-se o afastamento de qualquer extremismo na formulação de juízos sobre o texto, como alguns estudiosos que realizaram uma espécie de "colonização" da obra, Candido afirma: "com efeito, sociólogos, psicólogos e outros manifestam às vezes intuitos imperialistas, tendo havido momentos em que julgaram poder explicar, apenas com os recursos das suas disciplinas, a totalidade do fenômeno artístico". (CANDIDO, 1967, p. 21)

Antonio Candido, então, realiza uma crítica sociológica peculiar, já que diferentemente de boa da crítica de cunho sociológico, Candido formula seu juízo considerando o valor estético do texto. Dessa maneira, ao mencionar a terminologia estrutura, é importante considerarmos o valor inerente à forma como se apresenta na análise crítica, ou seja, na dialética entre a maneira 
interna e externa, como foi dito anteriormente. Assim, enquanto no estruturalismo a singularidade do texto fica comprometida com as generalizações de estruturas que coexistem para além da realidade da obra, negando-se à história, o pensador brasileiro focaliza a integração da história no valor artístico. Em relação à crítica sociológica e suas desvantagens, Luiz Costa Lima, explica: "usualmente, o sociólogo se defronta para a obra literária (ou artística) sem se preocupar com sua qualificação artística”. (LIMA, 2002, p. 662). Por outro lado, Candido sublinha o valor artístico do objeto, contrariando, por exemplo, o método de Sílvio Romero, o qual segundo o modelo de Taine, não soube revelar a forma como questões sociais se efetivam no interior da obra. Segundo Candido:

O seu defeito está na dificuldade de mostrar efetivamente, nesta escala, a ligação entre as condições sociais e as obras. Daí quase sempre, como resultado decepcionante, uma composição pararela, em que o estudioso enumera os fatores, analisa as condições políticas, econômicas, e em seguida, fala das obras segundo as suas intuições ou os seus preconceitos herdados, incapaz de vincular as suas ordens da realidade. (CANDIDO, 1967, p. 10)

Fala-se em valorização do aspecto que torna a realidade o componente necessário na conjuntura ficcional. Para os estruturalistas, fatores sociais são diluídos em fenômenos linguísticos, enquanto em Candido o sistema singulariza-se como redução estrutural, considerando um "processo de cujo intermédio a realidade do mundo e do ser se torna, na narrativa ficcional, componente de uma estrutura literária" (CANDIDO, 2004, p. 09). De acordo com Candido, o fenômeno não pode ser considerado apenas como dado linguístico, porque subsiste em sua tessitura interna com um social pertinente ao estético. O crítico chama atenção para os erros em que muitos estudiosos são levados, ao desviarem o verdadeiro objetivo que é o texto em valor artístico. Neste caso, a literatura não pode nunca servir à história, como em um ato imperialista, antes, deve projetar-se como valor que explica os vários casos concretos, isto é, como se desenvolvem ao longo do enredo. Além disso, faz-se mister esclarecer a preocupação exagerada com a obra, como objeto autônomo, fazendo-se com que o crítico caia em dogmatismos e falsos argumentos, como formula o crítico: "outro perigo é que a preocupação do estudioso com a integridade e a autonomia da obra exacerbe, além dos limites cabíveis, o senso da função em detrimento dos aspectos históricos - dimensão essencial para apreender o sentido do objeto estudado". (CANDIDO, 1967, p. 08) 
Assim, a perspectiva histórico-sociológica em Antonio Candido constitui-se em matéria de análise literária dialética, na medida em que se revela os condicionantes que permitem a valorização da obra, realizando-se a partir de uma matriz coerente e integral, não preferindo um aspecto em detrimento do outro. Dessa maneira, abordar o texto apenas como veículo sociológico, preso às camadas sociais e não valorizar a obra como objeto estético, é cair em incoerência crítica. A proposta de Candido caracteriza-se como "nível de análise, em que a estrutura constitui o ponto de referência, as divisões pouco importam, pois tudo se transforma, para o crítico, em fermento orgânico de que resultou a diversidade coesa do todo". (CANDIDO, 1967, p. 07, grifo nosso). Para Candido, a singularidade e a autonomia da obra dá-se como filtro social, no qual se desenvolve a individualidade estética de cada texto, diferenciando-se da crítica do século XIX, a exemplo de Sílvio Romero no Brasil, em que "anulava a individualidade da obra, integrando-a numa visão demasiado ampla e genérica dos elementos sociais". (CANDIDO, 1967, p.16)

A crítica postulada por Candido, elabora-se em dialética, em que o externo tem como fundamento ou papel para o interno da obra, isto é, na medida em que se articula para a constituição do efeito artístico. Desse modo, a crítica aqui exposta não se enquadra nas antigas postulações que considerava o social como fator fundante, influenciadora da obra, como é visto no determinismo, assim como recusa o viés que garante a autonomia numa perspectiva formal exacerbada, em que o cerne encontra-se na independência de qualquer manifestação externa. Por outro lado, o crítico esclarece que ambas são inoperantes na análise do texto, vistas isoladamente, devendo ser antes uma abordagem que "pretende ir mais fundo, sendo basicamente a procura dos elementos responsáveis pelo aspecto e o significado da obra, unificados para formar um todo indissolúvel”. (CANDIDO, 1967, p. 05).

Vale ressaltar, ainda, que Antonio Candido afirma que a sociologia condenada pela crítica a partir do século XX, é aquela que tudo tentava explicar como articulação social, o sociologismo crítico. De sorte que é sempre possível a abordagem pela "lente sociológica", desde que articulada como elemento que opera internamente à obra, assim, tal fato explica a própria mudança no estudo da sociologia, como observa Candido: "falar hoje em ponto de vista sociológico nos estudos literários deveria significar coisa bastante diversa do que foi a cinquenta anos". (CANDIDO, 1967, p. 08).

Percebe-se uma profunda consciência do crítico brasileiro em relação à manifestação da obra como objeto artístico, compreendendo-o em possibilidades de análises que o aborda como íntegro, em seu sentido autônomo, mas ao mesmo tempo ligado à história e suas matrizes, as 
quais se colocam no interior do fenômeno literário, contrapondo-se, então, da crítica sociológica praticada por muitos críticos, os quais foram "condenados" por Candido.

Em relação à crítica sociológica, Luiz Costa Lima, afirma: “As desvantagens resultam de o seu praticante não ter, enquanto analista da literatura, uma concepção específica de seu objeto." (LIMA, 2002, p. 661). Assim, a novidade do pensamento de Candido consiste em sua preocupação com o movimento dialético, e, sendo leitor do New Criticism e da antropologia funcional inglesa, soube operar na obra, ou seja, com consciência no que diz respeito aos elementos que verdadeiramente funcionavam ao interpretar um texto. Em boa parte, a falha de muitos críticos de cunho sociológico, devia-se à maneira ilustrativa em que se propuseram à literatura, registrando-a como mero documento social, uma espécie de manifesto da realidade imediata. Sobre essas duas realidades, a literatura como da ordem da consciência linguística e a da sociológica, a qual foi matéria de reflexão de Candido, Luiz Costa Lima também argumenta:

A linguagem é uma produção por certo conectada, mas dotada de regras de funcionamento próprio, que são da competência do lingüista. Sobre estas regras gerais se acrescentam regras outras, já não de ordem lingüística, que dizem respeito ao funcionamento dos discursos e dos gêneros. Não levar em conta a existência desta dupla ordem de regras levará ao reducionismo sociologizante ou, caso só a primeira ordem seja ressaltada, ao reducionismo formalizante. (LIMA, 2002, p. 664)

Antonio Candido, para isso, utiliza-se do caso de Senhora, romance do escritor José de Alencar, o qual, segundo o crítico, apresenta marcas de dimensões sociais, como costumes e evidencias claras de comportamentos particulares do período em que o texto foi escrito. Em Senhora, o casamento e as formas materiais que se colocam em torno do matrimônio, por exemplo, é a clave de toda a narrativa do escritor cearense. Assim, ao estudioso, interessa como esses fatores sociais articulam-se para formar um todo orgânico na obra, isto é, como o componente social é referido em composição organizacional do texto, e não como mera ilustração, como fica evidente no seguinte trecho de Literatura e Sociedade: "nem apenas ilustrada como exemplos, mas sugerida na própria composição do todo e das partes, na maneira por que organiza a matéria, a fim de lhe dar uma certa expressividade”. (CANDIDO, 1967, p. 07). 
Candido, portanto, organizando seu juízo crítico no que tange aos textos literários, pensa-os a partir do não excesso, indiciado pelos exageros do "sociologismo crítico" ou de escolas que defendem com exacerbação a autonomia da obra. O professor devolve-lhes o caráter de liberdade, em que é possível escolher coerentemente a melhor maneira interpretativa, além disso, "uma crítica que se queira integral deixará de ser unilateralmente sociológica, psicológica ou linguística, para utilizar livremente os elementos capazes de conduzirem a uma interpretação coerente". (CANDIDO, 1967, p. 07)

A coerência de que fala Candido, refere-se à maneira como o social integra-se na obra, fazendo com que o externo seja levado à categoria de elemento interno ao texto. O método dialético do crítico fundar-se-á como uma resposta às velhas perguntas, por exemplo, que trata a literatura como mimesis, termo importante nas reflexões desde a Antiguidade Clássica, sendo reelaborada também em formato de pergunta por Lukács no século XX, como é possível ler no seguinte fragmento: "O elemento histórico-social possui, em si mesmo, significado para a estrutura da obra, e em que medida?" (LUKÁCS apud CANDIDO 1967, p. 04). O históricosocial em Candido, revela-se nas obras, como foi dito, como processo criador, e ao mesmo tempo, constitui-se na falha de muitos críticos, como explica o professor: "Ao se interessarem pelos fatores sociais e psíquicos, procuram vê-los como agentes da estrutura, não como enquadramento nem como matéria registrada pelo trabalho criador". (CANDIDO, 1967, p. 05). Vejamos um trecho de Senhora, de José de Alencar, para tentarmos perceber como o social coexiste internamente à narrativa:

_ Já vejo que a senhora não é nada lisonjeira. Está desmerecendo nos meus dotes, acudiu a menina sublinhando a última palavra com um fino sorriso de ironia. Então não sabe, D. Firmina, que eu tenho um estilo de ouro, o mais sublime de todos os estilos, a cuja eloquência arrebatadora não se resiste? As que falam como uma novela, em vil prosa, são essas moças românticas e pálidas que se andam evaporando em suspiros; eu falo como um poema: sou a poesia que brilha e deslumbra!

_ Entendo o que você quer dizer; o dinheiro faz do feio bonito, e dá tudo, até saúde. (ALENCAR, 1970, p. 14-15)

Em Senhora, o dinheiro coloca-se como "motor" ao longo da narrativa, evidenciadas até mesmo na divisão dos capítulos do romance, como verificamos na divisão das partes: “O Preço", "Quitação", "Posse" e "Resgate". Vê-se um enredo em que o capital e a força do 
dinheiro são fundamentais para as relações, neste caso, o casamento, que deixa, muitas vezes, de carregar uma certa áurea romântica, para internalizar jogos de poder. De Acordo com Candido, "o próprio assunto repousa sobre condições sociais que é preciso compreender e indicar, a fim de penetrar no significado" (CANDIDO, 1967, p. 06).

Nesse sentido, da crítica, é preciso uma análise de como tais fatores são condicionantes para a estrutura interna da obra; como o capitalismo e a posse, por exemplo, são articuladores de ironia no discurso dos personagens, assim como a realidade concreta do dinheiro e do dote são elementos que modificam maneiras ou paradigmas na forma da escrita, como o que se dá entre realismo e romantismo, inclusive. Vale ressaltar que em José de Alencar muitos fatos que poderiam levar a total desvalorização moral dos sujeitos, acaba levando-os para qualquer tipo de redenção. Em Machado de Assis, por outro lado, essas perspectivas são revistas, e os homens são entregues às quedas. Vejamos outro trecho de Senhora, capítulo "Preço", em que o financeiro desenvolve-se no interior do discurso:

Convencida de que todos os seus inúmeros apaixonados, sem exceção de um, a pretendiam unicamente pela riqueza, Aurélia reagia contra essa afronta, aplicando a esses indivíduos o mesmo estalão.

Assim, costumava ela indicar o merecimento relativo de cada um dos pretendentes, dando-lhes certo valor monetário. Em linguagem financeira, Aurélia cotava os seus adoradores pelo preço que razoavelmente poderiam obter no mercado matrimonial. (ALENCAR, 1970, p. 11)

Em Senhora, as relações humanas são postas em processo de deterioração moral dos sujeitos, os quais envolvidos em questões econômicas, são mergulhados em artimanhas e secretas reviravoltas fundamentadas na posse. A partir do assunto dinheiro, Candido explica o paradoxo externo inerente ao interno, em que o valor da posse é garantia da manutenção do poder. Em relação à heroína, o professor sublinha: “A heroína, endurecida no desejo de vingança, possibilitada pela posse do dinheiro, inteiriça a alma como se fosse agente duma operação de esmagamento do outro por meio do capital, que o reduz a coisa possuída" (CANDIDO, 1967, p. 06). O crítico afirma tratar-se de um enredo em que transações, como numa bolsa financeira, são realizadas como fundamento do tipo de relações humanas, colocadas em destaque a partir do casamento, onde a burguesia aparece exposta. Vemos, portanto, um analista que se interessa, sobretudo pela composição do enredo, e não apenas nos fatores externos, em que constantemente é visto como uma espécie de tratado em muitos estudiosos 
demasiadamente engajados em assuntos, elaborando-os fora da análise interna. Sobre a composição de Senhora, e paradoxo externo e interno, o autor de Formação da literatura brasileira, explica:

\footnotetext{
Se, pensando nisto, atentarmos para a composição de Senhora, veremos que repousa numa espécie de longa e complicada transação, _ com cenas de avanço e recuo, diálogos construídos sobre pressões e concessões, um enredo latente de manobras secretas. (CANDIDO, 1967, p. 06)
}

Senhora é um retrato daquela sociedade que se modificava, em que o interesse é mola propulsora da manutenção e joguetes de poder. Os heróis e heroínas, dessa maneira, são capturados pela lógica capitalista, mas em José de Alencar, como se sabe, a outra lógica romântica ainda persiste como paradigma, como vemos, por exemplo, também em Lucíola, cujo nome lembra Lúcifer, personagens em latência de paradoxo, ou seja, aqueles que nascem da luz e vivem nas trevas, ou ao contrário. Segundo Candido, "as próprias imagens do estilo manifestam mineralização da personalidade, tocada pela desumanização capitalista, até que a dialética romântica do amor recupere a sua normalidade convencional" (CANDIDO, 1967, p. 06).

A expressividade e composição do enredo, então, dá-se dentro da particularidade capitalista, no interior da compra e venda e do acúmulo do poderio humano, isto é, da capacidade financeira sobre o outro, em que se encontra em jogo a liberdade. Desse modo, temos aqui a internalização do externo na obra, constituída também na recepção, como fica claro no final da "fábula", base do enredo, o qual Antonio Candido defende como influenciadora da manifestação artística. No capítulo "A literatura e a vida social” de Literatura e sociedade, o crítico afirma: "Não desejo aqui propor uma teoria sociológica da arte e da literatura, nem mesmo fazer uma contribuição original à sociologia de ambas, mas apenas focalizar aspectos sociais que envolvem a vida artística e literária nos seus diferentes momentos". (CANDIDO, 1967, p. 21)

\section{CONSIDERAÇÕES FINAIS}

Antonio Candido, crítico de formação sociológica e estudioso da antropologia inglesa, assim como da teoria da literatura, interessou-se pela maneira como o social expressava-se na obra 
literária, a qual classificava como dialética entre os elementos externos e internos. Para o crítico brasileiro, muitos estudiosos de viés sociológico, inclusive Georg Lukács, historiador literário húngaro, já partilhara de tentativas no que tange às análises de textos em sua expressividade e composição do fator externo internalizado na construção dos enredos, como demonstra o fragmento: "Em muitos críticos de formação sociológica já se nota o esforço de mostrar essa interiorização dos dados da natureza social, tornados núcleo de elaboração estética" (CANDIDO, 1967, 15). Em Senhora, do escritor cearense José de Alencar, Candido analisou as particularidades pelo qual o dinheiro e o poder evidenciados pelos casamentos são postos como fator de expressão, em um processo que envolve paradigmas de composição, como o Romantismo, e movimentos que se imbricam no capitalismo. Dessa dupla dialética, é que temos nuances de comportamentos, por exemplo, de personagens, como Aurélia, em que o jogo das análises pelo capital, pois, projetam-se em discursos em que o dinheiro é o principal motor de destruição moral, ou ainda, no caso de José de Alencar, de redenção, como postulam os finais românticos, isto é, em pleno movimento de perdão de culpas e retorno à moralidade.

\section{REFERÊNCIAS BIBLIOGRÁFICAS}

ALENCAR, José de. Senhora. São Paulo: EDIGRAF, 1970.

CANDIDO, Antonio. Literatura e Sociedade: estudos de teoria e história literária. 2. ed. São Paulo: Nacional, 1967. . Na sala de aula. 8. ed. São Paulo: Ática, 2005.

. O discurso e a cidade. 3. ed. São Paulo: Duas Cidades; Rio de Janeiro: Ouro sobre Azul, 2004.

LÉVI-STRAUSS, Claude. A estrutura e a forma. In: Antropologia estrutural dois. Trad. Maria do Carmo Pandolfo. 4. ed. Rio de Janeiro: Tempo Brasileiro, 1993, pp. 121-151.

LIMA, Luiz Costa. A Análise sociológica da literatura. In: Teoria da literatura em suas fontes. Organização, Seleção e Introdução de Luiz Costa Lima. 3.ed. Rio de Janeiro: Civilização brasileira, 2002, pp. 659-687. 2.v.

PIQUER, David Viñas. Historia de la crítica literaria. Barcelona: Ariel, 2002. 